\title{
Experimental indicators of ergonomic wellness and quality of life: salivary and hair cortisol
}

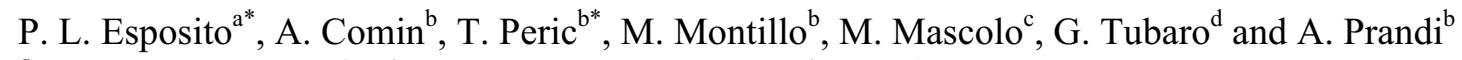
${ }^{a}$ SPRINT, University of Udine, via Petracco 8, 33100 Udine, Italy

${ }^{b}$ Department of Food Science, University of Udine, via Sondrio 2, 33100 Udine, Italy

${ }^{c}$ Department of Neurology, Hospital of San Giorgio, via Gemelli 10, 33170 Pordenone, Italy

${ }^{d}$ Department of Civil Engineering and Architecture, University of Udine, via delle Scienze 206, 33100 Udine, Italy

${ }^{*}$ Keywords: hair, cortisol, saliva, wellness, ergonomics.

\footnotetext{
${ }^{*}$ Corresponding author: tel.: +39 0432558371, fax: +39 0432558370, e-mail: tanja.peric@uniud.it
} 


\section{Introduction}

Salivary cortisol analysis has been widely used as a method for evaluating stress such as evaluation of the effectiveness of relaxation methods and labor environment assessment. However, this type of measurement has the inherent problem as timing of the sample, oral hygiene and the distance of sampling from the meal that can affect salivary cortisol level [1]. The biological material also need to be stored at $-20 \mathrm{C}^{\circ}$ and careful transport [2]. Recently also the hair has been used to measuring drugs [3], sex hormones [4] and to study HPA activity over a long period. The hair analysis can be considered a window to the past as it maintains a historical memory. Particularly hair cortisol level has potential as biological marker of chronic stress [5]. Hair sampling is not invasive method, hormone levels are not influenced by acute stress [6] as handling of the subject, samples can be stored at room temperature and easily sent to the lab. The sample does not decompose like other body fluids or tissues [7]. On the other hand limitations are given by the fact that till now it cannot be used to assess short-term hormone variations which may be affected, at least to a small extent, by the growth stage and rate of the hair [8], by the synthesis of local metabolites in hair follicles [9] and by seasonal variations [6].

The purpose of this study was to verify if the dayto-day variations of salivary cortisol can be monitored also in shaved hair.

\section{Materials and methods}

The experiment was performed on five healthy adult men. Saliva and hair samples were collected on three consecutive days, three times per day (at 8:00h - 11:00h - 23:00h). Hair samples were carefully obtained by shaving using electric razor and stored in dry tubes at room temperature until analysis. Hair cortisol assay was performed as described by Comin et al. [10].

Salivette ${ }^{\circledR}$ was used for collecting saliva samples. Participants were instructed not to eat, drink or brush their teeth $30 \mathrm{~min}$ before collecting saliva. Saliva samples were stored in a home freezer immediately after collecting. The samples were then centrifuge for $15 \mathrm{~min}$ at $1,500 \mathrm{~g}$. Cortisol concentration was measured by a RIA method as described by Comin et al. [10].

\section{Results}

The mean salivary cortisol concentration at $8: 00 \mathrm{~h}$ $-11: 00 \mathrm{~h}$ and $23: 00 \mathrm{~h}$ was $2.57 \pm 0.29 \mathrm{ng} / \mathrm{ml}-1,30 \pm$ $0.07 \mathrm{ng} / \mathrm{ml}-0.54 \pm 0.05 \mathrm{ng} / \mathrm{ml}$ (mean $\pm \mathrm{ES}$ ). Minimum and maximum values were 0.32 and 5.44 $\mathrm{ng} / \mathrm{ml}$

The mean hair cortisol concentration at 8:00h $11: 00 \mathrm{~h}$ and $23: 00 \mathrm{~h}$ was $39.12 \pm 1.12 \mathrm{pg} / \mathrm{mg}-28.19$ $\pm 1.44 \mathrm{pg} / \mathrm{mg}-23.44 \pm 1.63 \mathrm{pg} / \mathrm{mg}$ (mean $\pm \mathrm{ES}$ ). Minimum and maximum values were 12.46 and $45.96 \mathrm{pg} / \mathrm{mg}$.

Salivary and hair cortisol at $8: 00 \mathrm{~h}$ were significantly higher than cortisol level at 11:00h and 23:00h $(\mathrm{p}<0.001)$. Saliva and hair cortisol levels in the five healthy adult men are shown in Figure1. 


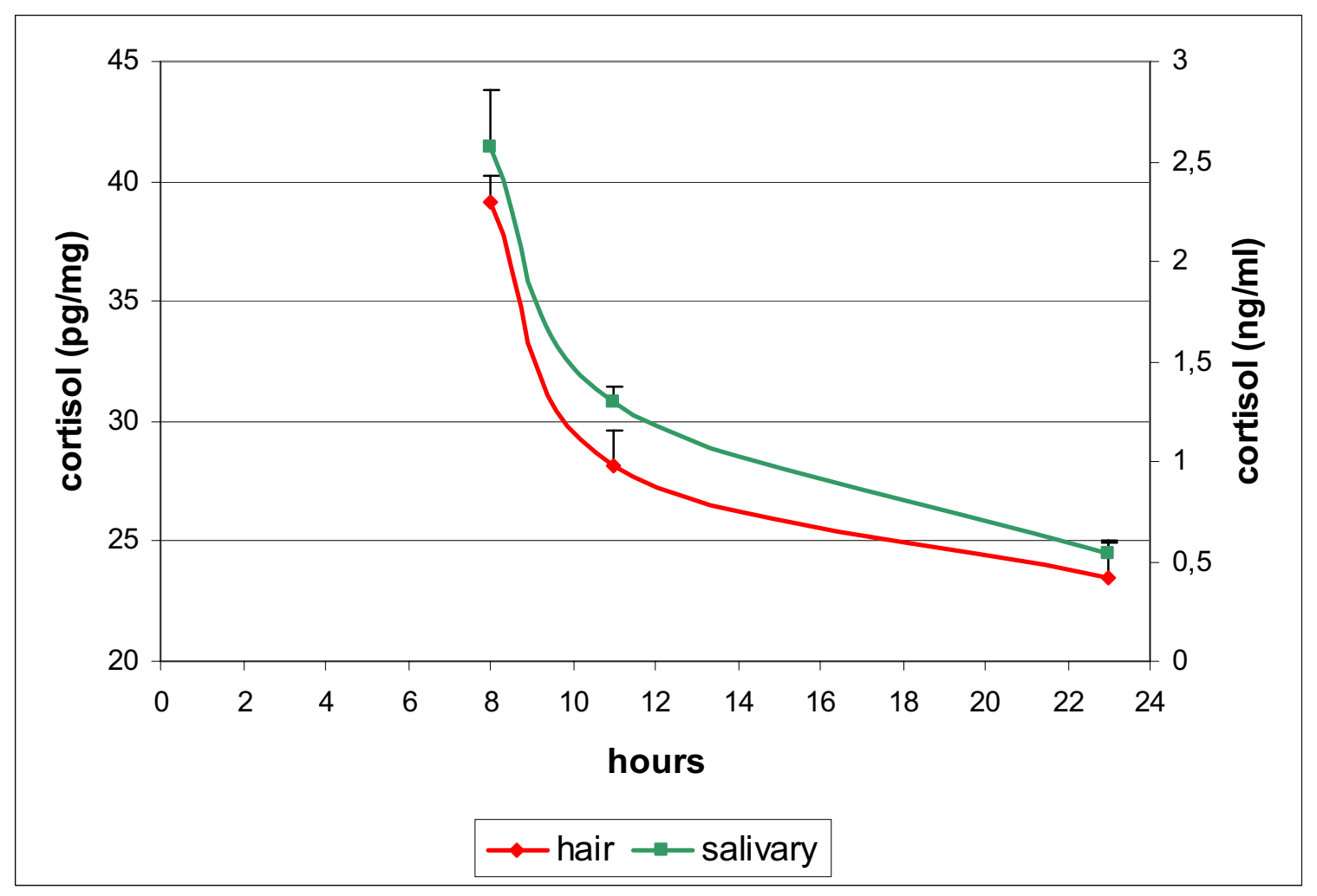

Fig.1. Saliva and hair cortisol levels.

\section{Discussion}

In this study we verified if the day-to-day variations of salivary cortisol can be monitored also in shaved hair. The difference in cortisol concentrations between saliva and hair are due to the fact that cortisol needs to enter the hair shaft during hair growth (the anagen phase) through passive diffusion from blood capillaries present on the basement membrane [11,12]. This study reveals a comparable trend between saliva cortisol and hair cortisol. Salivary and hair cortisol concentrations were highest in the morning during the first collection at $08: 00 \mathrm{~h}$, decreased throughout the course of the day and reached its lowest concentrations in the late evening as described in literature [13].

This similar cortisol profile leads us to say that hair can be used for evaluate day-to-day cortisol variation as saliva. Thereafter, the diversity of the biological sample does not affect cortisol evaluation.
This approach give objective information about HPA activation on daily and long period and could be applied for ergonomic scientific research purposes. Hair cortisol concentration measurements can be used to evaluate long term variations but also day-to-day variation of the HPA activity in discomfort, wrong type of life, the use of inappropriate daily equipment in house or office and the quality of life.

\section{References}

[1] P.T. Ellison, Measurements of salivary progesterone, Ann. N. Y. Acad. Sci. 694 (1993), 161-176.

[2] R. Gatti and E.F. De Palo, An update: salivary hormones and physical exercise, Scand. J. Med. Sci. Sports 21 (2011), 157169.

[3] P. Kintz, Testing for anabolic steroids in hair: a review, Leg. Med. (Tokyo) Suppl. 1 (2003), S29-33.

[4] L. Koren, O. Mokady, T. Karaskov, J. Klein, G. Koren, E. Gleffen, A novel method using hair for determining hormonal levels in wildlife, Anim. Behav. 63 (2002), 403406. 
[5] J. Yamada, B. Stevens, N. de Silva, S. Gibbins, J. Beyene, A. Taddio, C. Newman, G. Koren, Hair cortisol as a potential biologic marker of chronic stress in hospitalized neonates, Neonatology 92 (2007), 42-49.

[6] B. Sauvé, G. Koren, G. Walsh, S. Tokmakejian, S.H. Van Uum, Measurement of cortisol in human hair as a biomarker of systemic exposure, Clin. Invest. Med. 30(5) (2007), E183191.

[7] M. Balikova, Hair analysis for drugs of abuse. Plausibility of interpretation, Biomed. Pap. Med. Fac. Univ. Palacky Olomouc Czech Repub. 149 (2005), 199-207.

[8] Y. Nakahara, M. Shimamine, K. Takahashi, Hair analysis for drugs of abuse. III. Movement and stability of methoxyphenamine (as a model compound of methamphetamine) along hair shaft with hair growth, J. Anal. Toxicol. 16(4) (1992), 253-257.

[9] N. Ito, T. Ito, A. Kromminga, A. Bettermann, M. Takigawa, F. Kees, R.H. Straub, R. Paus, Human hair follicles display a functional equivalent of the hypothalamic-pituitary-adrenal (HPA) axis and synthesize cortisol, FASEB J. 19(10) (2005), 1332-1334.

[10] A. Comin, A. Prandi, T. Peric, M. Corazzin, S. Dovier, S. Bovolenta, Hair cortisol levels in dairy cows from winter housing to summer highland grazing, Livestock Science 138 (2011), 69-73.

[11] F. Pragst and M.A. Balikova, State of the art in hair analysis for detection of drug and alcohol abuse, Clin. Chim. Acta 370 (2006), 17-49.

[12] S. Steudte, T. Stalder, L. Dettenborn, E. Klumbies, P. Foley, K. Beesdo-Baum, C. Kirschbaum, Decreased hair cortisol concentrations in generalised anxiety disorder, Psychiatry Res. 186 (2006), 310-314.

[13] S. Matsuda, T. Yamaguchi, K. Okada, A. Gotouda, S. Mikami, Day-to-day variations in salivary cortisol measurements, J. Prosthodont. Res. (2011), doi:10.1016/j.jpor.2011.04.004 